\title{
BEM-ESTAR PSICOLÓGICO: O ESTADO DA ARTE DA SUBJETIVIDADE DOS COMPORTAMENTOS DE POLICIAIS MILITARES
}

\author{
doi>10.33726/akdpapers2447-7656v10a62020p32-52
}

\author{
FIGUEIREDO, Mari Lucia ${ }^{1}$
}

\begin{abstract}
RESUMO: O objetivo deste estudo foi o de investigar, por intermédio de uma metodologia de revisão da literatura, o que nos têm informado as pesquisas sobre o bem-estar psicológico de policiais militares, bem como, a quantas anda a subjetividade de seus comportamentos. Adicionalmente, verificamos e detalhamos a incidência de tais estudos em suas relações com o trabalho do policial como precipitador de sofrimento psíquico e implicações na sua saúde mental. A hipótese de trabalho norteadora da pesquisa, num dado instante, deveria ser a da dificuldade para se coletar dados dentro de uma corporação, onde a hierarquia e os protocolos são calcados em estereótipos que distorcem a visão de que o profissional de segurança pública é tão frágil e suscetível ao sofrimento como outro cidadão. Em nossa abordagem, realizamos um levantamento da produção científica nacional, veiculadas entre os anos de 2007-2014, especialmente aquelas que tratassem da temática relacionada à atividade do policial militar. A partir dos dados obtidos, fizemos considerações sobre o panorama geral de tais estudos donde se observou que, apesar da significativa produção nacional relacionada ao tema aqui proposto, outro fator que nos deixou preocupados foi a questão da violência, a qual deveria também ser tratada como questão de saúde pública referente a esses profissionais. Os resultados são pouco abrangentes, particularmente se comparados à relevância social da proposta.
\end{abstract}

PALAVRAS-CHAVE: Policiais militares, subjetividade, saúde mental

\begin{abstract}
The aim of this study was to investigate, through a literature review methodology, what has informed us about research on the psychological well-being of military policemen, as well as how much the subjectivity of their behaviors is going. Additionally, we verify and detail the incidence of such studies in their relations with the police's work as a precipitator of psychological suffering and implications for their mental health. The guiding hypothesis of the research, at a given moment, should be that of the difficulty in collecting data within a corporation, where the hierarchy and protocols are based on stereotypes that distort the view that the public security professional is so fragile and susceptible to suffering as another citizen. In our approach, we carried out a survey of the national scientific production, broadcast between the years 2007-2014, especially those that dealt with the theme related to the activity of the military police. From the data obtained, we made considerations about the general panorama of such studies, where it was observed that, despite the significant national production related to the theme proposed here, another factor that left us concerned was the issue of violence, which should also be treated as public health issue regarding these professionals. The results are not very comprehensive, particularly if compared to the social relevance of the proposal.
\end{abstract}

KEYWORDS: Military policemen, subjectivity, mental health

\footnotetext{
1 Graduada em Psicologia. Doutora em Psicologia como Profissão e Ciência. PUC - Pontifícia
} Universidade Católica de Campinas. E-mail: maripsydra@yahoo.com.br mari.figueiredo@uemg.br 


\section{INTRODUÇÃO}

Tomando como pressuposto a natureza complexa da subjetividade dos comportamentos de policiais e a relação com o bem-estar físico, mental e psicossocial, é que optamos por essa temática. Isto é, a partir de uma premissa como esta:

O conceito de polícia, como hoje a entendemos no Ocidente, foi fruto das modificações proporcionadas pela Revolução Industrial, que revolucionou não apenas o modo de produzir da humanidade, como também as relações sociais existentes. A Revolução Industrial e a expansão do capital permitiram a consolidação da polícia enquanto instituição de controle social, onde os problemas sociais eram fruto do capitalismo selvagem, que se caracterizava pela super exploração da classe trabalhadora forçada a viver em condições subumanas. A luta pela sobrevivência levou a massa explorada, não alocada nos centros de produção, a delinquir cada vez mais, aumentando às tensões sociais (SANTOS; SAMPAIO \& CERQUEIRA, s.d, p. 07).

Esse é um assunto bastante intrigante, pois nos coloca diante de um fato de que o trabalho do policial militar depende, intimamente, muito mais do que a sua força ou coragem, de condições psicológicas que lhe garantam certo bemestar diante de tarefas humanamente muito complexas.

Podemos pensar, então, que olhar o outro com neutralidade é algo simples, especialmente porque esse estudo é proveniente das ciências humanas, área em que, lidar com a subjetividade e com os aspectos qualitativos é inerente à grande maioria dos trabalhos. Desse modo, esse tema foi se consolidando sob um olhar absolutamente desprovido de neutralidade, necessário à pesquisa e também à psicologia que, de alguma forma, foi a responsável pelo aumento de nosso interesse.

Além das razões citadas, a escolha do tema bem-estar psicológico de policiais militares, visando à subjetividade do seu comportamento dentro da organização de trabalho, deve-se à própria evolução de nossa linha de pesquisa desenvolvida no meio universitário. Por isso, o enfoque adotado nos trabalhos acadêmicos sempre esteve ligado a pesquisas organizacionais. No início, diagnóstico organizacional, depois, motivação e liderança criativa e, por fim, clima para criatividade (CRESPO, 2005). 
Portanto, o motivo que nos levou ao presente estudo, foi se concretizando a partir do momento em que percebemos a existência de dificuldades no tratamento dos problemas humanos dentro das corporações militares. Nesses contextos, inserem-se a presente proposta, cujo objetivo geral se coaduna com a revisão de literatura sobre o bem-estar psicológico de policiais militares e subjetividade de comportamento, com intuito de subsidiar a realização de estudos futuros, em que se avaliem outras variáveis que podem afetar o bem-estar psicológico desses profissionais.

\section{O BEM-ESTAR PSICOLÓGICO}

O Bem-Estar Psicológico (BEP) é um construto baseado na teoria psicológica, agregando conhecimentos da psicologia do desenvolvimento humano, da psicologia humanista-existencial e da saúde mental.

A respeito do funcionamento psicológico positivo ou ótimo (RYFF, 1989), os pontos de convergência entre essas formulações teóricas constituem as dimensões do BEP, quais sejam: a autoaceitação, as relações positivas com os outros, a autonomia, o domínio sobre o ambiente, o propósito na vida e o crescimento pessoal (RYFF, 1989; RYFF \& KEYES, 1995; RYFF \& SINGER, 2008).

Decorrente destas constatações, a Psicologia Positiva surgiu como modelo de investigação, cujo objetivo principal seria o de estudar as características humanas que contribuem para o seu ótimo desenvolvimento (GONÇALVES \& LEITE, 2009; ROSA \& HUTZ, 2008). A Psicologia Positiva, no contexto de nossa investigação, sugere que os defeitos e as qualidades das pessoas sejam explorados conjuntamente.

Seligman (2003; 2004) identificou os três principais pilares que sustentam a Psicologia Positiva: a) as emoções positivas ou experiências subjetivas; b) os traços positivos ou características individuais, tais como as forças pessoais e virtudes, a exemplo das habilidades do tipo inteligência e da capacidade atlética; e, c) as instituições e comunidades positivas, como família, trabalho, democracia, de onde podem emergir forças e virtudes que conduzem 
a pensamentos positivos (GONÇALVES \& LEITE, 2009; PALUTO \& KOLLER, 2007).

O primeiro pilar que identifica a experiência subjetiva refere-se às emoções positivas (FREDERICKSON, 2002) e às experiências ocorridas no passado (DIENER, 2000), ou seja, especificamente o que nos interessa focar aqui sobre os estudos do bem-estar subjetivo. Assim é, que, Rosa (2006) argumenta que o bem-estar subjetivo é mencionado pela literatura através de termos como "afeto positivo", "satisfação" e "estado de espírito". Já, Diener (1996), afirma que o bem-estar subjetivo está relacionado à forma pela qual as pessoas avaliam suas vidas. Em suam, vê-se que se trata de um construto que "diz respeito a como e porque as pessoas experienciam suas vidas positivamente" (ROSA \& HUTZ, 2008, p. 02).

Para Chaves (2007) sob a perspectiva da Psicologia Positiva, posta sob o prisma do campo do bem-estar subjetivo, revelam experiências como: satisfação, autorrealização, contentamento, felicidade, esperança, traços individuais positivos, perseverança, talento e sabedoria são aspectos ligados à positividade do ser humano que são retratados e analisados por essa teoria.

Referindo-se ao bem-estar subjetivo, Gonçalves \& Leite (2009) dizem que este tópico é formado por quatro componentes: satisfação com a vida, afetos positivos e negativos e felicidade. Salientam ainda tais autores, que um dia o salário já foi garantia de satisfação do trabalhador, entretanto, isto já deixou de ser suficiente. Para os mesmos autores, as horas de descanso, o convívio com a família, o reconhecimento, são fatores primordiais na vida dos seres humanos que devem ser enaltecidos pelas organizações (incluindo as instituições militares).

Em outra perspectiva, Machado \& Bandeira (2012) dizem que o BemEstar Psicológico é um construto multidimensional, estrutura que reflete características relativas ao funcionamento psicológico positivo ou ótimo. Os autores afirmam, por sua vez, que, ao basear-se na teoria psicológica, reúne avanços conceituais e achados empíricos de décadas de pesquisas nas áreas do desenvolvimento humano, da psicologia humanista-existencial e da saúde mental. 
Do ponto de vista metateórico, o BEP representa uma retomada da tradição eudaimônica, de onde advém o estudo do bem-estar, resgatando, com isso, o sentido original do bem-viver na doutrina aristotélica. A expressão grega eudaimonia fora equivocadamente traduzida, empregando-se 0 vocábulo "felicidade", desconsiderando-se diferenças fundamentais entre hedonismo e eudaimonismo, e suas implicações teóricas no estudo do bem-estar (RYAN \& DECl, 2001; RYFF, 1989; WATERMAN, 1993).

A preocupação no que constitui o bem viver tem sido tema de investigação na civilização ocidental desde os antigos filósofos gregos. Porém, a inclusão do estudo do bem-estar em nível psicológico no âmbito da investigação científica se deu na década de 60, eivada por grandes transformações sociais e pela necessidade de desenvolver indicadores sociais de qualidade de vida (MACHADO \& BANDEIRA, 2012). Nessa época, psicólogos sociais e do comportamento observaram que, até então, as doenças mentais e o sofrimento humano eram o foco principal das investigações, porém, sabia-se pouco sobre saúde mental e felicidade (DIENER, 1985; RYFF, 1988).

O modelo do Bem-estar Psicológico surgiu no final da década de 80, com o trabalho de Ryff (1989), na tentativa de definir a estrutura básica do bem-estar ao nível psicológico (MACHADO, PAWLOWSKI \& BANDEIRA, 2013). Aristóteles, em sua doutrina ética, propõe que o bem-estar resulta da eudaimonia, isto é, provém da ação em direção ao desenvolvimento dos potenciais únicos de cada pessoa (RYFF, 1989; WATERMAN, 1993).

Outras formulações sobre a essência do bem-estar são previstas em termos de experiências de prazer, de contentamento, de satisfação e de felicidade, isto é, BES (Bem-Estar subjetivo). Assim, se assemelham à concepção hedônica (por exemplo, a de Aristipo de Cirene) do bem-viver, donde provém a satisfação dos desejos, a busca pelo prazer e a evitabilidade da dor (RYAN \& DECI, 2001; WATERMAN, 1993).

Em relação à definição do bem-estar psicológico, Nascimento (2006) diz que é uma percepção de compromisso com os desafios existenciais da vida e um nível pleno de funcionamento psicológico positivo, atuantes no sujeito, 
associado ao ajustamento emocional e social adequado, bem como a suficiente maturidade individual.

Conclui-se, portanto, que Machado \& Bandeira (2012, p. 589) relatam que as características que constituem a essência do BEP incluem: "possuir uma atitude positiva em relação a si mesmo e aceitar múltiplos aspectos de sua personalidade (auto aceitação); possuir relacionamentos acolhedores, seguros, íntimos e satisfatórios com outras pessoas (relações positivas com outros); ser autodeterminado, independente, avaliar experiências pessoais segundo critérios próprios (autonomia); ter competência em manejar o ambiente para satisfazer necessidades e valores pessoais (domínio sobre o ambiente); ter senso de direção, propósito e objetivos na vida (propósito na vida); perceber um contínuo desenvolvimento pessoal e estar aberto a novas experiências (crescimento pessoal)" (RYFF, 1989; RYFF \& KEYES, 1995; RYFF \& SINGER, 2008).

\section{O POLICIAL MILITAR}

Como falar do policial sem nos remetermos à farda que ele veste? Como desvinculá-lo da imagem repetidamente explorada, seja ela boa ou ruim, de herói ou vilão? Como olhar o indivíduo, humano, sem julgá-lo por atos de alguns (poucos ou muitos), sem recriminá-lo, sem dar a chance de acolhê-lo em seu sofrimento? (SILVA, 2009).

Para Poncioni (2005), no Brasil, a segurança pública sofre com uma realidade social que destaca o crescimento contínuo das diversas formas de violência e criminalidade. Esse autor relata, que as políticas adotadas pelas polícias civil e militar se mostram pouco eficazes no combate a essa situação e que as críticas acerca da segurança pública são muitas, principalmente no que se refere à atuação do policial.

São considerados servidores militares os indivíduos que, em caráter permanente ou transitório, prestam serviços militares no plano da administração da União e dos Estados. Sendo assim, pode-se dizer que os policiais militares se referem aos profissionais que desempenham atividade no âmbito federal ou no estadual, recebendo por este serviço um subsídio. 
A profissão do policial requer que este indivíduo atue no confronto contra a conduta irregular ou criminosa da sociedade, defendendo cidadãos. Para a realização de um bom exercício profissional, o militar deve saber lidar com o conjunto de tarefas a ele conferidas e não se abster de cumprir suas obrigações, mesmo que isso implique em algum dilema ideológico pessoal (GASPARINI, 2001; JESUS, 2001).

A atividade militar de policiamento, portanto, não se resume ao serviço diário, visto que a função implica em constante estado de alerta, mesmo quando o profissional esteja em momentos de descanso (MIRABETE, 1998; GUIMARÃES, 1999).

Mesmo assim, muitas vezes, os policiais são tidos pela população, ignorando este estado de alerta contínuo vivido pelo policial, como violentos e imprevisíveis. É claro que isso não institui justificativa para arbitrariedades, contudo, as pessoas, em sua quase totalidade, sobretudo aqueles que vivem em áreas periféricas e violentas ou em contextos de favelas, não confiam no policial, pois julgam que os mesmos apresentam conduta discriminatória, violenta e, por vezes, duvidosa diante da comunidade. Portanto, a figura do policial fica prejudicada, especialmente quando se considera que diversos policiais demonstram uma conduta profissional respaldada na ética e na responsabilidade de seus atos (SILVA \& LEITE, 2007).

Frente a esses impasses e a outros que devemos considerar, vale dizer que cabe ao policial a difícil conduta de distinguir entre o bem e o mal, dentro de uma ética geral e leiga imposta pela sociedade. Além disso, terá que decidir entre o legal e o ilegal, o justo e o injusto e entre o honesto e o desonesto, argumentam Rosa (2001) e Valla (2000). Porém:

[...] o fato é que, por conta dessas contradições e pela magnitude do descontrole, polícia é um tema que interessa a todos, a menos que você tenha mais de quarenta anos, seja branco e rico, e não disfarce a sua origem de classe. Mesmo assim, você terá parentes e amigos mais jovens ou será sensível aos dramas que o cercam com uma frequência assustadora. Pensando bem, mesmo rico e branco, ou melhor, por conta desses atributos, é melhor você se preocupar também, porque a competência policial é decisiva para desmontar as quadrilhas de sequestradores, assim como o controle dessa corporação é necessário para evitar que policiais participem dos sequestros (SOARES, 2000). 
As pessoas normalmente esperam do policial um atendimento de qualidade e, sobretudo, humanizado, o que é muito pertinente, pois, quem se encontra em algum tipo de perigo, portanto, fragilizado psicologicamente, necessita de um atendimento por um policial preparado nesses aspectos (COSTA, 2007). Mas, o que observamos dentro da instituição Militar é que não existe um trabalho efetivo de promoção à saúde mental, que venha dar condições para esse policial lidar com questões nesse aspecto.

A partir disso, se desencadeia a dificuldade na prestação de um atendimento de qualidade e humanizado e no lidar com pessoas de diversas culturas, condição que se agrava diante das reclamações por parte da população, segundo relatos de estudos de pesquisas nacionais apresentados a seguir.

Refletindo sobre essas e outras dificuldades sobre o sofrimento psíquico dos policiais militares e a ausência do bem-estar, encontramos um estudo de Fraga (2008), relatando as representações sociais dos acidentes de trabalho ocorridos na polícia militar. O título desse estudo é "A Polícia Militar Ferida". Nele, a autora diz, que o fracasso que permeia um acidente de trabalho entra em choque com a cultura militar instituída para o culto do saudável, do forte e do herói. Para a autora, no momento em que um policial vivencia um acidente de trabalho, as marcas deste acontecimento acabam por atingir não só a vítima, mas se estende para a família, a Instituição polícia e para a sociedade.

Podemos levar esse questionamento para as inter-relações laborais, familiares e, sobretudo, para o próprio indivíduo que aqui, até agora, está sendo citado como um profissional, representante de uma Instituição, com diversas atribuições e responsabilidades. Oliveira (2011), entretanto, ao analisar tal situação, argumenta que o sujeito deve ser analisado dentro do contexto de suas afetações, emoções e subjetividades, fazendo com que não incorramos no erro de apresentar uma pesquisa em saúde mental voltada apenas para a preocupação com o rendimento profissional desse sujeito, mas com o próprio sujeito em si.

A primeira constatação a que chegamos é a de que "saúde é o estado de completo bem-estar físico, mental e social e não apenas a ausência de doença" (OMS, 1948). 
Já, para Scliar (2007), saúde é condição que reflete a conjuntura social, econômica, política e cultural, ou seja, não representa a mesma coisa para todas as pessoas. Dependerá de contextos como época, lugar e classe social, bem como, de valores individuais, concepções científicas, religiosas e filosóficas. Podendo-se, inclusive, nos permitir pensar o mesmo das doenças, ou seja, dependendo do contexto em que o indivíduo se insere:

Pensando o ofício policial a partir dessa perspectiva, não é difícil deduzir que se trata de uma categoria profissional bastante vulnerável à produção de sofrimento psíquico, uma vez que o exercício do trabalho é marcado por um cotidiano em que a tensão e os perigos estão sempre presentes (SPODE \& MERLO, 2005, p. 86).

É fato que, para o indivíduo ingressar na corporação, o mesmo é submetido a testes psicológicos e físicos que avaliam se ele tem pré-requisitos para assumir tal função, porém, após seu ingresso na corporação, não há um trabalho efetivo voltado para o acompanhamento da saúde mental do mesmo (CIASP, 2012). Esses e outros procedimentos, em suma, são desconhecidos pela própria sociedade, circunstância em que a mesma é clientela primeira deste profissional, cuja principal função é o atendimento e a segurança da sociedade.

\section{MÉTODO}

A metodologia que foi utilizada consiste em levantamento e revisão bibliográfica, tratando da narrativa associada ao tema da polícia e do bem-estar psicológico e sua subjetividade. Realizou-se uma consulta através da busca nos bancos de dados do Scielo e Bireme, a partir das fontes Medline e Lilacs. Foram encontrados 11 artigos nas bases de dados consultadas que versavam sobre o tema citado acima.

As pesquisas sobre bem-estar com policiais militares, em quase sua totalidade, foram realizadas no ambiente universitário, em forma de teses ou artigos, segundo critério de inclusão. Consideramos as publicações constantes no período de 2007 a 2014, portanto, referem-se aos últimos sete anos. 


\section{PESQUISAS NACIONAIS SOBRE BEM-ESTAR SUBJETIVO COM POLICIAIS MILITARES}

Silva (2009) relata, que a questão do mal-estar psicológico ocasionado pelas vivências profissionais do policial militar perecem ser claras. Há muito se fala sobre os efeitos da violência na população geral, em como a sensação de insegurança pode provocar reações psicológicas graves. A autora argumenta que, quando voltamos estes olhos ao profissional que trabalha diretamente com esta temática, é possível constatar que os estudos se tornam mais escassos, apesar do significativo aumento de publicações com estas temáticas, especialmente visíveis a partir dos anos 2000.

As considerações apresentadas pelos autores acenam para algumas indagações relevantes. Por isso, um trabalho como o nosso se justifica, na medida em que seria interessante avaliar como está a produção científica, cujo tema relaciona-se ao policial militar, concentrando nele o foco precipitador de sofrimento psíquico e as implicações na sua saúde mental, além da constituição de sua subjetividade.

Paulino \& Lourinho (2014) afirmam que, na perspectiva de subsidiar o desenvolvimento de uma Política Estadual de melhoramento das condições de trabalho e de promoção de uma boa qualidade de vida, relatam que o objetivo principal do estudo foi o de entender o processo de adoecimento psicológico dos trabalhadores policiais militares, de modo a identificar os fatores determinantes e condicionantes desse infortúnio laboral, e descobrir como a Organização Polícia Militar e seus agentes desenvolvem a qualidade de vida no trabalho.

Como estratégias metodológicas complementares, os autores citados relatam que foram adotados três procedimentos: pesquisa documental, acompanhamento do cotidiano de trabalho e realização de entrevistas semiestruturadas dirigidas aos policiais militares que desempenham diferentes funções:

O adoecimento mental dos policiais militares do Estado do Ceará não é diferente do adoecimento dos policiais militares de outros Estados, nem suas causas são diferentes das já especificadas pelos diversos autores que tratam do tema em tela. Mas, também, a não busca pela instituição (Policia Militar do Ceará) da solução para o problema, é um fator que se 
evidencia. A grande questão dessa problemática é a inexistência de um mecanismo de verificação sistemática que possa identificar o aparecimento desses fatores de adoecimento, para que, no início, seja estabelecida uma forma de combate ou controle, evitando, assim, o acometimento crônico do policial militar a esses fatores doentios (PAULINO \& LOURINHO, 2014, p. 74-75).

Também nesse foco de investigação, Silveira \& Souza (2014) abordaram a concepção de policiais militares acerca do estresse, na perspectiva da saúde mental. Analisaram a questão, qualitativamente, através da ferramenta da "Análise do Discurso". Nisso, anotaram suas conclusões, a partir da fala dos sujeitos da pesquisa, quais sejam: três policiais militares - um soldado feminino, um masculino e um sargento.

Os resultados apontaram para um policial consciente da importância do buscar e da promoção dos serviços e cuidados de saúde mental. No entanto, percebe-se que, aqueles que não o fazem, tendem a atribuir a conduta a vários fatores, tais como a precariedade destes serviços prestados pela instituição.

A pesquisa traz, ainda, apontamentos da fragilidade desses serviços dentro da Instituição Policial Militar, pontuadas pelos próprios policiais, sinalizando para a importância de outras pesquisas dentro desse tema, as quais pudessem contribuir para uma melhor compreensão dos dados emergidos e de quais implicações esse "não buscar e não promover" dos serviços e cuidados de saúde mental, possam ter sobre esses policiais, suas famílias, a instituição e a sociedade.

Portanto, abre-se, assim, a possibilidade de novos olhares e fazeres na promoção e cuidados em saúde mental para o policial militar e, consequentemente, para toda sociedade.

Souza (2013) corrobora, entre os bombeiros e policiais militares, a prevalência do processo pelo qual as relações entre o bem-estar subjetivo e a saúde mental e o bem-estar subjetivo e o burnout (um estado de tensão emocional e estresse crônico provocado por condições de trabalho desgastantes), adquirem significado psicológico, a partir do afeto mediador das crenças do autoeficácia. Segundo os procedimentos relatados por Souza (2013), para a coleta de dados, utilizaram-se os seguintes instrumentos: Questionário de Saúde Mental (QSG-12), Maslach Burmout Inventory-Student 
Survey (MBI-SS), Escala de Auto Eficácia Percebida Geral Percebida, Escala de Afetos Positivos e Negativos, Escala de Vitalidade Subjetiva e Escala de Satisfação com a Vida. A pesquisa foi desenvolvida com um total de 228 cadetes militares, cuja maioria é do sexo masculino $(79 \%)$.

Informa Souza (2013), que o estudo demonstrou que quanto ao bemestar subjetivo, apesar de estarem expostos às contingências diversas e adversas, os cadetes militares conseguem manter níveis equilibrados de saúde mental. Isso, em boa parte, devido à dinâmica dos quatros tipos de funções mediadoras (cognitiva, seletiva, afetiva e reguladora).

Outro dado interessante apontou para o fato de que a relação entre 0 tempo na corporação e a saúde mental pode ser completamente explicada pelo critério da autoeficácia. Já, em relação ao burnout, apesar de conviverem no mesmo ambiente acadêmico (CEPMPB), cadetes policiais e cadetes bombeiros apresentam divergências em relação ao burnout, sendo que os cadetes da PM apresentam maior nível de burnout do que os cadetes BM.

Outro achado importante, foi o de que, quanto mais tempo eles ficam na corporação, mais aumenta a probabilidade de estes virem a desenvolver a síndrome de burnout.

Em outro estudo, Souza, Minayo, Silva \& Pires (2012) investigaram os fatores associados ao sofrimento psíquico dos policiais militares da cidade do Rio de Janeiro, no Brasil. A partir de estudo transversal, realizado com 1.120 policiais, foram caracterizados o perfil socioeconômico e demográfico, a qualidade de vida, as suas condições de saúde e de trabalho. Para mensurar o sofrimento psíquico, utilizou-se o Self-Reported Questionnaire.

$\mathrm{Na}$ análise de associações, usou-se o modelo de regressão logística, considerando-se variáveis relacionadas ao sofrimento psíquico. Os resultados indicaram associação entre sofrimento psíquico e fatores como: capacidade de reagir a situações difíceis e grau de satisfação com a vida; problemas de saúde, sobretudo, digestivos, nervosos, musculares e ósseos; e condições adversas de trabalho, como carga excessiva, constante exposição ao estresse e à vitimização.

Conclui-se, apontando a necessidade de intervenções que visem à promoção da saúde desses profissionais, sobretudo da sua saúde mental. 
Voltado para a análise sobre estresse e qualidade de vida de bombeiros militares, Prado (2011) elaborou uma pesquisa, cujo objetivo principal foi o de detectar a prevalência de Estresse e a Qualidade de Vida em Bombeiros Militares de um quartel do interior do estado do Mato Grosso do Sul.

A amostra é oriunda de 33 pessoas de um grupamento, em um universo de 42 convidados, militares que trabalham no Setor Operacional. Utilizou-se o método de pesquisa quantitativo, descritivo e de corte transversal. Os dados foram coletados por meio da aplicação de três instrumentos: o Questionário Sociodemográfico para a caracterização da população estudada, com as variáveis, idade, sexo, posto e graduação nas relações de trabalho, Inventário de Sintomas de Stress para Adultos de Lipp, que investiga a prevalência do estresse, nas fases - Alerta, Resistência, Quase-exaustão e Exaustão - e a sintomatologia predominante, física e/ou psicológica.

Para avaliar a Qualidade de Vida Geral, foi utilizado o questionário WHOQOL-breve, da Organização Mundial da Saúde, que faz investigações através dos domínios dos aspectos Físicos, Psicológico e as Relações Sociais. Os resultados demonstraram que os bombeiros pesquisados, em sua maioria, não apresentam estresse e a percepção sobre a qualidade de vida se classifica entre boa a excelente.

Outra investigação com policiais militares foi desenvolvida por Oliveira \& Bardagi (2010) sobre estresse e comprometimento com a carreira. A referida pesquisa desenvolveu um estudo comparativo dos níveis de estresse e comprometimento na carreira de policiais militares de Santa Maria (RS), divididos de acordo com a função desempenhada, tais como: atendimento pelo número 190 (pelo telefone), serviços administrativos e policiamento ostensivo.

Os instrumentos foram um questionário sociodemográfico, uma Escala de Comprometimento com a Carreira e um Inventário de Sintomas de Estresse para adultos, respondidos por 75 participantes, homens e mulheres, entre $22 \mathrm{e}$ 44 anos. Verificou-se que $(57,3 \%)$ dos participantes apresentaram sintomatologia de estresse e que as mulheres apresentaram maior severidade nos sintomas.

Os funcionários administrativos apresentaram maior comprometimento com a carreira do que os demais grupos. Estes resultados confirmam que a 
atividade militar se insere em um contexto de vulnerabilidade e indicam que, quanto maior o risco envolvido, menor é a segurança em relação à carreira. Assim, tornam-se fundamentais propostas de intervenção que favoreçam as estratégias de enfrentamento.

Explorar a percepção de policiais militares da força tática e de rua acerca dos aspectos que permeiam sua saúde mental foi o objetivo do estudo de Oliveira \& Santos (2010). Participaram dele 24 policiais militares de dois Batalhões da Polícia Militar do Estado de São Paulo. Para aqueles que consentiram na participação, foi aplicado individualmente uma escala com 30 questões, abordando assuntos relativos ao tema. Os resultados evidenciaram que os participantes (91,7\%), sempre ou às vezes, percebiam-se estressados; uma parte $(41,7 \%)$ relatou já ter agido impulsivamente em alguma ocorrência; $(88,3 \%)$, sempre ou às vezes, se sentiam emocionalmente cansados após o dia de trabalho; (62,5\%) afirmaram que, às vezes, percebiam-se agressivos no trabalho; $(20,8 \%)$ já pensaram em suicídio e $(8,3 \%)$ nunca se sentiam realizados com a profissão. Sugere-se a necessidade de novos estudos.

Silva \& Vieira (2008) são autoras que se interessaram pela saúde mental de policiais militares. Foi desenvolvido um estudo objetivando relacionar o processo de trabalho dos policiais com a saúde mental. As autoras buscaram contextualizar as finalidades dos serviços de segurança pública via breve histórico da polícia estadual, sua divisão e aplicabilidade frente à violência cotidiana.

Por intermédio de substratos advindos da psicologia do trabalho, usaram técnicas e conceitos fundamentados na Ergonomia da Atividade e na Psicodinâmica do Trabalho: observação do processo de trabalho, pesquisa documental, entrevistas individuais e coletivas.

A análise, de natureza qualitativa, demonstrou que o policial militar está no centro de uma conjugação de forças ocorridas na organização do trabalho, na precarização do trabalho e, por fim, na sociedade contemporânea. As formas como essas relações de forças se conjugam, contribuem para implicações danosas à saúde (mental) dos profissionais, cuja configuração favorece o aumento do sofrimento psíquico, podendo se desdobrar em alcoolismo, depressão e, até mesmo, em suicídio. 
Dados da Junta Médica, de 2003 a 2005, mostram uma média de 489 policiais militares afastados do serviço por licenças médicas. Trata-se de números preocupantes, especialmente por ser em uma área de serviço público essencial à população. Esses números seriam maiores se as liberações ocorridas no local de trabalho também fossem computadas. O procedimento de liberação interna ocorre para tentar mediar os possíveis longos períodos na atividade para tratamento de saúde.

O estudo elaborado por Frutas (2007), cujo objetivo principal foi o de construir um conhecimento sobre a relação entre significado do trabalho e bemestar de policiais militares bombeiros, teve como eixo condutor a Teoria das Representações Sociais. Como suporte complementar, balizou-se nos estudos de saúde mental sob a perspectiva da subjetividade e do trabalho.

O pressuposto foi a maneira como o bombeiro atribui significado em seu trabalho, em maior ou menor escala, o que determina o bem-estar ou sofrimento desse profissional. Através das análises das entrevistas realizadas, a pesquisadora concluiu que, apesar das inúmeras representações de sofrimento que permeiam o trabalho do bombeiro, o seu bem-estar é sustentado pela forma como atribui significado ao seu trabalho, sendo este respaldado na "paixão" pelo trabalho realizado e no reconhecimento social e familiar que a profissão Ihe proporciona.

A autora também considerou que a Corporação dos Bombeiros é uma instituição que possui uma imagem bem definida no imaginário social e que se distingue pela simpatia e o reconhecimento da sociedade. Fato este que contribui para a atribuição de significado ao trabalho do bombeiro.

E, por fim, em 2007, Costa apresentou um estudo em que o objetivo foi o de diagnosticar, nos policiais militares da cidade de Natal, o nível e a fase de estresse em que se encontravam e qual a sintomatologia prevalente (física ou mental). Foi um estudo descritivo, com corte transversal, no qual foi investigada uma amostra de 264 indivíduos, extraída de uma população de 3.193 Militares do Comando de Policiamento da Capital - CPC, da cidade de Natal/RN.

Os dados foram coletados através do Inventário de Sintomas de Stress para Adultos de Lipp-ISSL. Constatou-se a existência de $(52,6 \%)$ de policiais sem sintomas de estresse e $(47,4 \%)$ com sintomatologia de estresse, 
distribuídos em todos os postos hierárquicos, com destaque para os grupos de oficiais superiores e intermediários, bem como cabos e soldados, com predominância na fase de resistência (36\%) e de prevalência de sintomas psicológicos (76\%). Das variáveis investigadas, a única que apresentou relação de estresse foi o sexo $(P=0,0337)$.

Conclui-se, então, a existência de estresse nos policiais, em todos os postos hierárquicos, com destaque para os grupos de oficiais superiores e intermediários, cabos e soldados, com prevalência de sintomas psicológicos, baixos níveis de sintomas físicos, com predominância na fase de resistência.

\section{CONSIDERAÇÕES FINAIS}

O presente estudo teve como objetivo principal revisar a literatura que versa sobre os estudos relacionados ao bem-estar psicológico de policiais militares e subjetividade de comportamento.

Apesar de se revestir de um caráter introdutório e metodologicamente se pautar por um levantamento bibliográfico, o presente estudo permite delinear alguns aspectos envolvidos na relação causal entre a atividade policial e a saúde mental. Nesse sentido, a própria delimitação da categoria profissional pode contribuir para suscitar a realização de outras pesquisas sobre o tema, de modo a respaldar intervenções em prol da saúde no trabalho policial.

Podemos observar que as pesquisas e reflexões sobre o bem-estar psicológico da Polícia Militar ainda caminham a passos lentos. Além de enfrentar os resquícios da ditadura militar, a Instituição em voga é uma organização burocrática, com raízes no século XIX. A Polícia Militar traz, na sua base, os princípios da hierarquia e da disciplina que remontam certa ancestralidade, em face de procedimentos mais contemporâneos de organização estatal, social, política.

A esse respeito, Silva (2003) afirma que a humanização da estrutura dos policiais brasileiros é o principal veículo para se democratizar a Segurança Pública no país. E ressalta que a sensibilização vivencial empreendida pode alcançar bons resultados nessa direção, uma vez que constitui metodologia aplicável a grupos similares (policiais militares, forças armadas, bombeiros e 
outros), cuja missão é a de garantir a segurança pública, mas não exercem plenamente esse papel pelos diversos atravessamentos a que estão sujeitos.

Percebe-se através das pesquisas apresentadas que, dentro do militarismo, não existem medidas preventivas ou políticas públicas efetivas e eficazes que proponham uma melhor estruturação das ações que objetivam a melhoria da qualidade de vida e a saúde mental do policial militar.

Tais constatações, no entanto, vão além do processo de trabalho em si, tendo em vista que precisam de reflexões sobre os salários, do processo de organização institucional, dos cuidados dispensados à saúde e das condições de vida pessoais e familiares desses servidores.

Merece atenção especial os policiais que, pelas suas características de personalidade e pelo excesso de exposição ao risco e à vitimização, desenvolvem sintomas agudos e crônicos de sofrimento psíquico e de estresse cumulativo.

Todos os estudos aqui abordados apontam para a necessidade de implementação de medidas concretas e preventivas, no sentido de melhorar e fortalecer esses policiais, particularmente quando eles vivenciam problemas no cotidiano e em momentos de grandes tensões, visando, não apenas, mas também, ao melhor desempenho técnico e a maior qualidade de vida para eles e suas famílias.

Ressaltamos, finalmente, a importância da realização de pesquisas que possam respaldar ações transformadoras, o que redundará em favor da corporação e do próprio policial, mas, sobretudo, da sociedade que precisa contar com a efetividade dos serviços desses profissionais. 


\section{REFERÊNCIAS}

BALESTRERI, R. B. Direitos Humanos: coisa de polícia. Passo Fundo: Ed. CAPEC, 2003.

COSTA, M. A. A. Estresse - Um diagnóstico dos policiais militares da cidade de natal - Brasil. Tese apresentada à Universidade Federal do Rio Grande do Norte para obtenção do título de doutorado em ciências da saúde pelo programa de pós-graduação em ciências da saúde, Natal, p. 1-69, 2007.

CHAVES, S. S. S. O bem-estar subjetivo e os valores humanos em músicos e advogados da cidade de João Pessoa. Tese de Doutorado. Universidade Federal do Rio Grande do Norte: Natal - RN, 2007.

CRESPO, M. L. F. Construção e validação de um instrumento de clima para criatividade nas organizações empresariais. Tese de Doutorado: Pontifícia Universidade Católica - Campinas, 2005.

DIENER, E., EMMON S, ROBERT A., LARSEN, R. J., \& GRIFFIN, S. The satisfaction with life scale. Journal of Personality Assessment, 49 (1), 71-75, 1985.

DIENER, E., EMMON S, ROBERT A., LARSEN, R. J., \& GRIFFIN, S. Subjective well-being in cross-cultural perspective. In: H. Grad (Eds). Key issues in cross-cultural psychology: selected papers from Twelf International Congress of the International Association for Cross-Cultural Psychology ( $p$. 319-330). Champaign-Urbana: IL, 1996.

DIENER, E., EMMON S, ROBERT A., LARSEN, R. J., \& GRIFFIN, S. Subjective well-being: The science of happiness, and a proposal for a national index. American Psychologist, 55 (1), 34-43, 2000.

FRAGA, C. K. Peculiaridade do trabalho do policial militar. Revista Virtual \& Contexto, 5 (2), 2008.

FREDERICKSON, B. L. (2002). The role positive emotions in positive psychology: The broaden-and-build theory of positive emotion. American Psychologist, 56, 218-256, 2002.

FRUTOS, F. P. P. Vivenciando o bem-estar, enfrentando o sofrimento: estudo da representação social do bombeiro sobre o significado do seu trabalho. Dissertação de Mestrado: Universidade Estadual de Londrina - Universidade Estadual de Maringá, Paraná, 2007.

GASPARINI, D. Direito administrativo. São Paulo: Saraiva, 2001.

GONÇALVES, S. M. M., \& LEITE, A. P. T. T. Bem-estar subjetivo no trabalho: contribuições da psicologia positiva para a gestão de pessoas. In: VI Simpósio de Excelência em Gestão e Tecnologia - SEGeT Resende. SEGeE/artigos, 2009. 
GOUVEIA, V. V., BARBOSA, G. A., \& MASSUD, M. Bem-estar e saúde mental. In: G. A. Barbosa, E. O. Andrade, M. B. Carneiro, \& V. V. Gouveia (Eds.). A saúde dos médicos no Brasil, p. 29-48, 2007.

GUIMARÃES, A. F. O contrato de trabalho do policial militar. Revista Direito Milita da Associação dos Magistrados das Justiças Militares Estaduais, Florianópolis 3 (17), p. 6-8, 1999.

JESUS, F. Psicologia aplicada à justiça. Goiânia: AB, 2001.

MACHADO, W. L., \& BANDEIRA, D. R. (2012). Bem-estar psicológico: definição, avaliação e principais correlatos. Estudos de Psicologia, 29 (4), 587595, 2012.

MACHADO, W. L., PAWLOWSKI, J., \& BANDEIRA, D. R. Validação da Psychological Well-being Scale em uma amostra de estudantes universitários. Avaliação Psicológica 12 (2), 263-272, 2013.

MIRABETE, J. F. Processo Penal. São Paulo: Atlas, 1998.

NASCIMENTO, S. H. As Relações entre Inteligência Emocional e Bem-estar no Trabalho. Dissertação de Mestrado: Faculdade de Psicologia e Fonoaudiologia, Universidade Metodista de São Paulo, 2006.

OLIVEIRA, D. R. Atividade policial e sua relação com a síndrome de burnout. Revista Eficaz. Revista Científica Online, ISSN 2178-0552, 2011.

OLIVEIRA, K. L., \& SANTOS, L. M. Percepção da saúde mental em policiais militares da força tática e de rua. Sociologias, 12 (25), p. 224-250, 2010.

OLIVEIRA, P. L. M., \& BARDAGI, M. P. Estresse e comprometimento com a carreira em policiais militares. Boletim de Psicologia I LIX, (131), 153-166, 2010.

Organização Mundial de Saúde - OMS, 1948. Disponível em: http://www.casan.com.br/index.php?sys=9.

PALUDO, S. S., \& KOLLER, S. H. Psicologia positiva: uma nova abordagem para antigas questões. Paidéia, 17 (36), 9-20, 2007.

PAULINO, F. R., \& LOURINHO, L. A. O adoecimento psicológico do policial militar do Ceará. Revista Trabalho e Sociedade, 2 (2), p.58-77, 2014.

PONCIONI, P. O modelo policial profissional e a formação profissional do futuro policial nas academias de polícia do estado do Rio de Janeiro. Sociedade e Estado, 20 (3), p. 585-610, 2005.

PRADO, J. S. Estresse e qualidade de vida em bombeiros militares. Dissertação de Mestrado em Psicologia: Universidade Católica Dom Bosco, Campo Grande, 2011. 
ROSA, P. T. R. Regulamento disciplinar militar e suas inconstitucionalidades. Revista Direito Militar da Associação dos Magistrados das Justiças Militares Estaduais, 5 (29), p.16-18, 2001.

ROSA, F. H., \& HUTZ, C. S. Psicologia Positiva em ambientes militares: bemestar subjetivo entre cadetes do Exército Brasileiro. Arquivos Brasileiros de Psicologia, 60 (2), 15-171, 2008.

RYFF, C. D. Happiness is everything, or is it? Explorations on the meaning of psychological well-being. Journal of Personality and Social Psychology, 57 (6), 1069-1081, 1989.

RYFF, C. D., \& KEYES, C. L. M. The structure of psychological well-being revisited. Journal of Personality and Social Psychology, 69 (4), 719-727, 1995.

RYFF, C. D., \& SINGER, B. H. Know thyself and become what you are: a eudaimonic approach to psychological well-being. Journal of Happiness Studies, 9 (1), 13-39, 2008.

RYAN, R. M., \& DECI, E. L. On happiness and human potentials: a review of research on hedonic and eudaimonic well-being. Annual Review of Psychology, 52, 141-166, 2001.

SANTOS, A. S.; SAMPAIO, M. S., \& CERQUEIRA, W. L. Condições de trabalho e bem-estar dos Praças do $5^{\circ}$ Batalhão de Polícia de Guardas da PM/BA. Especialização em prevenção da violência. Universidade Federal da Bahia. (s.d.).

SCLIAR, M. História do conceito de saúde. PHYSIS: Rev. Saúde Coletiva, 17 (1): 29-41. Disponível em: http://www.scielo.br/pdf/physis/ v17n1/v17n1a03.pdf, 2007.

SILVA, D. A. Estresse policial no $3^{\circ}$ BPM da cidade de Cuiabá $-M T$. Monografia de Especialização em Gestão de Segurança Pública. Faculdade de Administração, Economia e Ciências Contábeis da Universidade Federal do Mato Grosso: Cuiabá, 2003.

SILVA, J. H. R. Estudo sobre o trabalho do policial e suas implicações na saúde mental. Dissertação de Mestrado: Instituto de Psicologia da Universidade de São Paulo, 2008.

SILVA, L. A. M.; \& LEITE, M. P. Violência, crime e polícia: o que os favelados dizem quando falam desses temas? Sociedade e Estado, 22 (3), p. 545-591, 2007.

SILVA, M. B., \& VIEIRA, S. B. O processo de trabalho do militar estadual e a saúde mental. Saúde e Sociedade, 17 (4), 2008.

SILVEIRA, C., \& SOUZA, L. V. F. (Psicologado.com/junho, 2014). Saúde mental e o policial militar: a concepção de policiais militares acerca do estresse relacionado ao seu trabalho dentro da perspectiva da saúde mental. Disponível em: https://psicologado.com/psicopatologia/saude-mental/saude-mental-e-o-policial- 
militar-a-concepcao-de-policiais-militares-acerca-do-estresse-relacionado-ao-seutrabalho-dentro-da-perspectiva-de-saude-mental @).

SOARES, L. E. Meu casaco de general: quinhentos dias no front da segurança pública no Rio de Janeiro. São Paulo: Companhia das Letras, 2000.

SOUZA, L. A. S. (2013). O papel do auto eficácia na saúde mental e no burnout de cadetes policiais e bombeiros militares. Tese de Doutorado: Universidade Federal da Paraíba e Universidade Federal do Rio Grande do Norte.

SOUZA, E. R., MINAYO, M. C. S.; SILVA, J. G., \& PIRES, T. O. Fatores associados ao sofrimento psíquico de policiais militares da cidade do Rio de Janeiro, Brasil. Cad. Saúde Pública, 28 (7),1297-1311, 2012.

SPODE, C. B.; \& MERLO, Á. R. C. O policial militar e a saúde mental: considerações acerca do trabalho dos capitães da brigada militar. In: R. M. J. Mendes; J. C. P. Consul; Fraga, C. K. (Eds). A visibilidade da segurança pública: risco no trabalho, formação e políticas. Porto Alegre: Gráfica Santa Rita, 2005.

VALLA, W. O. Ética e a atividade do policial militar. Revista Direito Militar da Associação dos Magistrados das Justiças Militares Estaduais, 4, (21), p. 5-6, 2000.

WATERMAN, A. S. Two conceptions of happiness: contrasts of personal expressiveness (Eudaimonia) and hedonic enjoyment. Journal of Personality and Social Psychology, 64 (4), 678-691, 1993. 